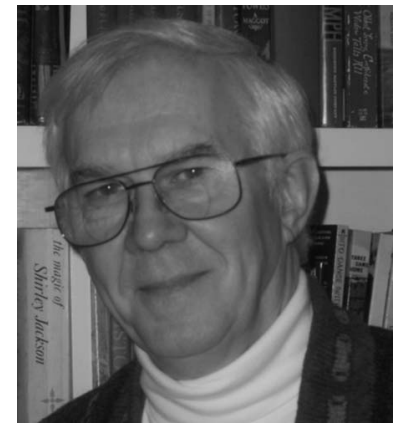

\section{National Inventors Hall of Fame}

In September I went home again. I returned to Akron, Ohio, to attend my 50th year high school class reunion. With a few exceptions I had to read my classmates' ID tags to see who I was talking to, but considering our age we've held up pretty well. The reception and dinner the next night were enjoyable events.

What was disconcerting during my visit was the further reduction in the vitality of this once vibrant town. I grew up among the tire factories that made Akron the Rubber Capitol of the World. When I was young I could see Firestone Tire and Rubber from our front porch; I went to St. Mary grade and high school just up the hill (and downwind) from B. F. Goodrich; and in my senior year I tested tires at General Tire across the expressway from Goodyear. When they do the autopsy on my lungs, they are going to find they have been vulcanized.

Today, the factories are empty or underused and the downtown is a shadow of what I remember as a kid when I was allowed to travel around the city by myself. The only expansion that I saw on this visit was the campus of the University of Akron. It has grown from a single city block when I was a student there to something six to ten times larger at the expense of the intown residential areas.

Usually our visits tend to be family-related and filled with activities. This time, because of the two reunion events, our Saturday morning was free so we could visit the National Inventors Hall of Fame located hard by the university. I have subscribed to the magazine Invention and Technology published by American Heritage since it began in 1985. In 2002 the museum was its underwriter and a column on the museum appeared in the magazine, so I looked forward to finally seeing it.

If I found the trip around Akron disconcerting, the trip to the museum was depressing. Although it is housed in an impressive building, what it held was not engaging. The major exhibit consists of three tiers of a doublerowed display of placards containing photographs and facts about the members of the National Inventors Hall of Fame. There are two other tiers on the patent system and the marketing of inventions. Supplementing the array of placards on the walls there are several substantial displays with videos on a few selected members. Perhaps the most engaging is one demonstrating the high-speed photographic feats of Harold "Doc" Edgerton for whom the SPIE ultrafast award is named. But beyond these few extended presentations a visitor gets no feel for the life of the inventor or the ingenuity or importance of his or her contributions.

Established in 1973, the museum was an outgrowth of a display in the U.S. Patent Office lobby in Arlington, Virginia. The exhibit of original patent models on the main floor of the museum in Akron was probably part of that original display. The labeling and tagging of the pieces are haphazard and, with the exception of a few wall-mounted exhibits, the visitors are left to puzzle things out for themselves. One the first level there is an exhibit floor that houses a children's activity area and a traveling exhibit gallery. The gallery contained an engaging display of inventions from the television series "Modern Marvels," which airs on the History Channel. As with any collection of inventions the range was wide and the motivations of the inventors reflected their life and need to solve a problem. It was the most compelling place in the museum that told visitors about the motivation and thought processes behind an invention.

But that alcove, tucked in the corner of the lowest floor, represents a small fraction of the larger static space. The museum opened more than 10 years ago, and given the nature of the major exhibit with its rows of placards, I thought, perhaps, a Web-based Hall of Fame might be more engaging and informative. That isn't so. The site, http://invent.org, is one of the most puzzling sites on the Web. Faced with a series of boxes with symbols that are activated by mouse-overs, browsing becomes an experiment. Perhaps that is supposed to be the nature of the site. Gaining information on the museum and its inductees is by no means transparent. If you find your way to one of the pages describing one of the members, you will find a small thumbnail photo or sketch of the inventor, a description of the invention, its impact, and a short biography. Other than the thumbnail there are no graphics, just text. The Web site does not extend or redeem the museum.

Some of my enthusiasms that I have discussed in editorials in this journal are the identification of the sources 
and the encouragement of curiosity and problem-solving since it is the heart of the practice of engineering. I have even mentioned my wish to visit the museum on these pages. But having done so, I am disappointed. I wish it were otherwise.

Could anything be done to improve things? Granted, the display of the members is the central exhibit. In this day of LCDs (their inventor, Jim Fergason from Kent State, is honored), the placard displays could, as time and money permits, be converted to presentations with animations and short items (quotations, biographical elements, images, etc.) that would provide visitors with insight into the inventors and their inventions. Having an entire wall of such displays all going at once would be unnerving, but static presentations that could be activated by the curious viewer along with a few playing at random would present a more compelling experience than the current placards. Perhaps the content could be generated for use on the Web first, and then, when developed, incorporated into the museum pieces.

A rather impressive building sits on the edge of downtown Akron. Intended to celebrate the inventive spirit, it seems to lack that itself. True, beyond the bricks and mortar the foundation that governs the museum sponsors invention programs for grade school and college students. The museum and its Web site should celebrate inventors and the value of the intellectual resources that support their efforts in a manner that engages the public.

Donald C. O'Shea Editor 